LAURA E. HAHN

Centre for Language Studies, Radboud University

MAAIKE TEN BUUREN

Radboud University

TINEKE M. SNIJDERS

Max Planck Institute for Psycholinguistics

PAULA FIKKERT

Centre for Language Studies, Radboud University

\title{
Learning words in a second language while cycling and listening to children's songs: The Noplica Energy Center
}

\footnotetext{
ABSTRACT

Children's songs are a great source for linguistic learning. Here we explore whether children can acquire novel words in a second language by playing a game featuring children's songs in a playhouse. The playhouse is designed by the Noplica foundation (www.noplica.nl) to advance language learning through unsupervised play. We present data from three experiments that serve to scientifically prove the functionality of one game of the playhouse: the Energy Center. For this game, children move three hand-bikes mounted on a panel within the playhouse. Once the
}

\section{KEYWORDS}

songs

movement

word learning

cycling

preschool

play 
children cycle, a song starts playing that is accompanied by musical instruments. In our experiments, children executed a picture selection task to evaluate whether they acquired new vocabulary from the songs presented during cycling. Two of our experiments were run in the field, one at a Dutch and one at an Indian preschool. The third experiment features data from a more controlled laboratory setting. Our results partly confirm that the Energy Center is a successful means to support vocabulary acquisition in a second language. More research with larger sample sizes and longer access to the Energy Center is needed to evaluate the overall functionality of the game. Based on informal observations at our test sites, however, we are certain that children do pick up linguistic content from the songs during play, as many of the children repeat words and phrases from the songs they heard. We will pick up upon these promising observations in future studies.

\section{INTRODUCTION}

Children's play is full of music and movement (Smith 2010). The combination of acoustic and physical activity is highly rewarding and contagious for children (Ilari 2015, 2018; Pellegrini 2012). The very nature of children's play might also be beneficial from an educational perspective (Golinkoff et al. 2006). Here we present a novel serious game that incorporates play, music and movement, to foster language learning in preschool children: the Noplica Energy Center.

\section{Language learning from songs}

Young children are drawn into songs due to the songs' captivating melodies and rhythms and catchy lyrics (Ilari 2015, 2018; Marsh and Young 2016). These positive features make songs a standard material in second language learning (Davis 2017; Engh 2013; Fonseca-Mora 2016). Furthermore, there is mounting evidence for musical training (Benz et al. 2016; Strait and Kraus 2011) and musical play (Linnavalli et al. 2018) to support auditory perception, thereby indirectly improving a range of language skills (Cohrdes et al. 2016; Elmer and Jäncke 2018). One theoretical framework to explain the benefit of music on language processing is provided by the OPERA hypothesis (Patel 2011, 2012 , 2014). This hypothesis rests on the fact that music and language share a great deal of their acoustic structure. The emotional-attentional and cognitive mechanisms engaged in processing children's songs could, therefore, transfer into the language domain. Hence, hearing a word in song lyrics could, in principle, lead to recognizing this word in speech as well. Yet, learning words from songs is not trivial: the words' acoustic shape is determined by the melody and rhythm of the song. This influences recognition and memorization of the word and, thus, to what extent the mental representation of a sung word transfers to the spoken modality (Calvert and Billingsley 1998; Coyle and Gomez Gracia 2014; Leśniewska and Pichette 2014). Nevertheless, we rely on songs' high social-emotional power (Cirelli et al. 2019; Trehub and Cirelli 2018) and investigate whether the Energy Center in the Noplica playhouse supports preschool children's acquisition of novel words in a second language.

\section{Language learning through movement}

Similarly to songs and music, movement also aids adults' and children's learning and well-being (Fisher et al. 2012; Herting 2018). Several studies report 
improved learning outcomes for educational settings that incorporated movement during instruction (Liu et al. 2017; Mavilidi et al. 2015, 2018; Schmidt et al. 2019). Both the frameworks of embodied and grounded cognition suggest that perception and action are intertwined (Barsalou 2008; Wilson 2002), with a tight relationship between the motor system and cognition. Nevertheless, the exact mechanisms that mediate physical activity and learning are still being debated (see, e.g. reviews by Barenberg et al. 2011 and Donnelly et al. 2017). Despite the prevalent awareness of the importance of movement and play during childhood (Fisher et al. 2008) and repeated call for policy changes in educational settings to promote movement during early years (Reilly et al. 2012), children in the western world do not move enough (Finger et al. 2018; Gezondheidsraad 2017; Griffiths et al. 2013). The Energy Center, as included in the Noplica playhouses, exemplifies one possible answer to this problem, as it allows for active unsupervised play with ample opportunities for movement.

\section{The Energy Center in the Noplica playhouse}

The Noplica foundation designed a set of games to stimulate language learning (www.noplica.nl). The language games are combined into a playhouse, of which prototypes have so far been installed in an orphanage in Maharashtra, India, and at schools in Rotterdam and Nijmegen, the Netherlands. So far, a Dutch and an English version of the playhouse have been created. The focus of the research presented here was on one of the games of the Noplica playhouse, the Energy Center (see Figure 1).

The Energy Center is targeted for children aged between 2.5 and 6 years. In this game, three children play together at a panel with three hand-bikes. Upon movement of the bikes, the vocals of a children's song start playing (the same song for all children) and colourful LED lights indicate how much

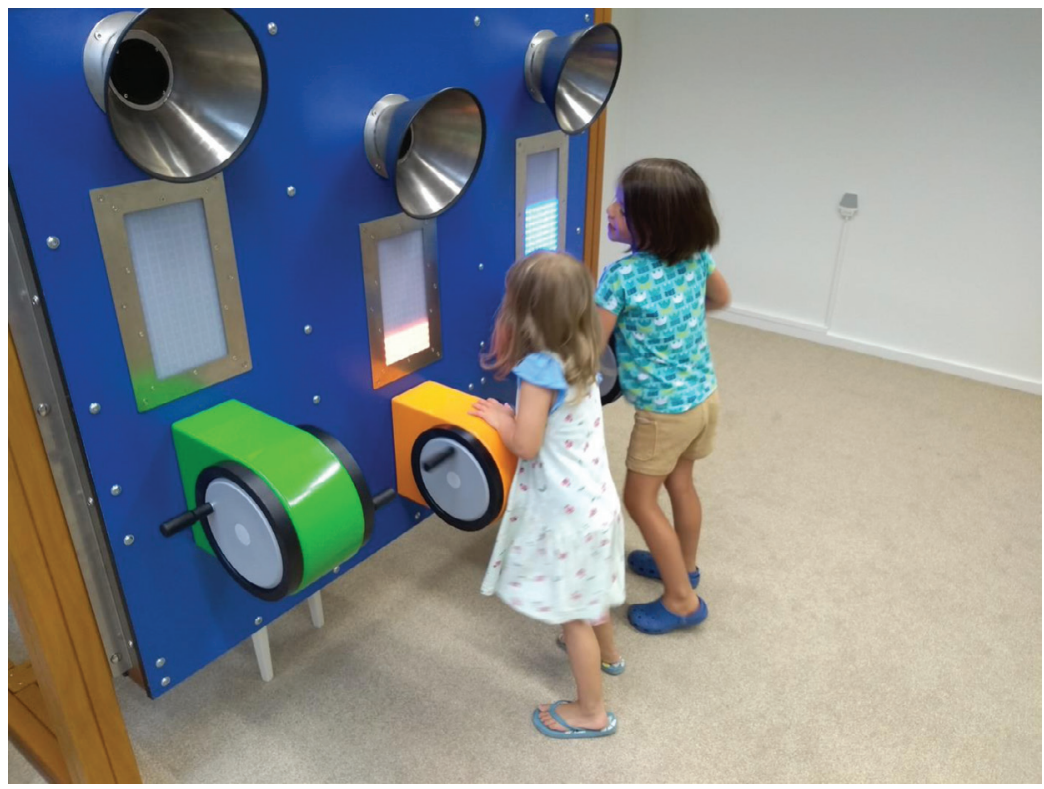

Figure 1: Energy Center (set up in a language lab, not in a playhouse), with two children playing and LED lights indicating the energy produced. 
energy each child produces, that is, how steady the child is cycling. Soon after the cycling has started and after enough energy has been produced, the song is accompanied by musical instruments. Each bike is associated with one instrument for each song; that is, child $\mathrm{A}$ on bike 1 may produce the piano for song I and the drums for song II and the trumpet for song III. The children can cycle for as long as they wish and get exposed to a set of twenty different songs. The songs feature different topics and vocabulary and are sung by male and female singers in a child-friendly way. During our informal observations at the prototypes, we saw children cycling eagerly, competing for the LED lights to go higher and higher and becoming submerged in the songs. Children also switched bikes during playing, cheered each other to cycle more and were clearly enjoying the game.

\section{The current study}

The aim of the current set of experiments was to investigate whether the Energy Center has a positive effect on children's vocabulary in their second language. That is, do children know more words after having cycled in the Energy Center (Experiments 1 and 2) or listened to the songs of the Energy Center (Experiment 3)?

Experiment 1 is a field study at a Dutch preschool with children that had Dutch either as their first language, but were at risk of language delay (henceforth L1-at risk) or learned Dutch as a second language (henceforth L2). Children had access to the Energy Center on the playground of their preschool and listened to twenty Dutch songs. Before and after playing, a picture-word matching task was run to investigate vocabulary growth.

Experiment 2 was run in a language laboratory in the Netherlands with monolingual Dutch children who did not know each other prior to the beginning of the study. Children visited the lab in groups of three and cycled in the Energy Center for approximately ten minutes. They were exposed to an English version of the songs. Again, a picture-word matching task was run to investigate whether the words featured in the songs of the Energy Center are recognized better than two other sets of novel words.

Experiment 3 was run at an Indian orphanage with preschool children of mixed-language background (mainly Hindi or Marathi). The design was the same as in Experiment 2 (English children's songs, picture-word matching task); however, this time children only listened to the songs while sitting in a circle, as the Energy Center was not yet installed at the field site.

\section{EXPERIMENT 1: FIELD STUDY WITH PRESCHOOLERS IN THE NETHERLANDS ACQUIRING DUTCH VOCABULARY \\ Method}

Fourteen preschoolers (seven females, mean age 3 years, range 2.0-4.0 years) were recruited from a Dutch day care and tested on their receptive vocabulary in Dutch before and after they had access to the Energy Center (Dutch version). Five additional kids were excluded due to being absent either during the post-test or the in-class activity. Participants had Dutch either as their first language (L1 group, $n=7$ ) or as their second language (L2 group, $n=7$ ). All children were diagnosed to be at-risk for language delays in Dutch, either because they did not receive enough Dutch input in the past (L2 group) or because they have (or are at risk of) speech language disorders of various 
kinds (L1 group). Henceforth the L1 group will be termed L1-at risk accordingly. Parents of participating children were informed about the aim and setup of the study within a letter. Parents gave written consent prior to the start of data collection. The pre- and post-test took place in a quiet corner within the common group room of the children. The Energy Center was installed on the playground of the day care. Children visited the Energy Center in groups of three to four once a week over the course of six weeks. Each group would play approximately ten minutes, so that each child accumulated an estimated average of 60 minutes of playing time in the Energy Center. The Energy Center featured a set of twenty children's songs with Dutch lyrics. The songs were playing in random order. A subset of three songs was additionally played in the classroom of the children for a single day. On this day, the three songs were repeated three to five times in a passive to semi-passive listening context, meaning that children were not listening attentively to the songs most of the time. Before and after the six-week playing period with the Energy Center, children were tested on their receptive vocabulary with a picture selection task (pre-/post-test). Children were asked to point at the correct picture in a panel of four pictures ( 30 trials, one per target word). Half of the target words came from the songs that were only played in the Energy Center $(n=15$, Energy Center context). The other half of the target words was featured in the three songs that were played in the Energy Center and additionally in the classroom $(n=15$, InClass context). The dependent variable was the difference in percentages of correct responses in the pre- and the post-test (vocabulary growth) for the two learning contexts (Energy Center, InClass) and the two language groups (L1-at risk, L2).

\section{Results}

Both language groups performed better during the post-test than during the pre-test in both learning contexts (see Figure 2). The L2 group also benefitted from the in-class exposure.

A non-parametric repeated-measures mixed $2 \times 2$ analysis of variance (ANOVA) (Wilcox 2012; Wilcox and Schönbrodt 2014) on the factors language status (L1-at risk, L2) and learning context (Energy Center, InClass) with vocabulary growth as the outcome variable revealed a significant interaction between language status and learning context $(F[1,7.2]=10.76, p=0.01)$ : the two language groups differed in the degree of vocabulary growth in the two learning contexts. The interaction was followed up by Yuen's $t$-tests on trimmed means for the two language groups on the factor learning context. In the L1-at risk group, there was no significant difference in vocabulary growth between the learning contexts $\left(M_{\text {diff }}=-7.99[-20.89,4.89], Y_{t}[4]=-1.72, p=0.16\right)$, while in the L2 group there was a significant difference $\left(M_{\text {diff }}=10.66\right.$ [1.54, 19.80], $\left.Y_{t}[4]=3.24, p=0.03\right)$.

Taken together, our results show that children benefitted from playing in the Energy Center, as they knew more words during the post-test than during the pre-test. For the L2 children, the benefit of playing in the Energy Center increased by the additional exposure to a subset of songs of the Energy Center in class. For the Energy Center to be successfully integrated into educational practice, the language background of the target group has to be taken into account.

The current experiment has two important methodological limitations: one is the small sample size, which was determined by the tight educational 


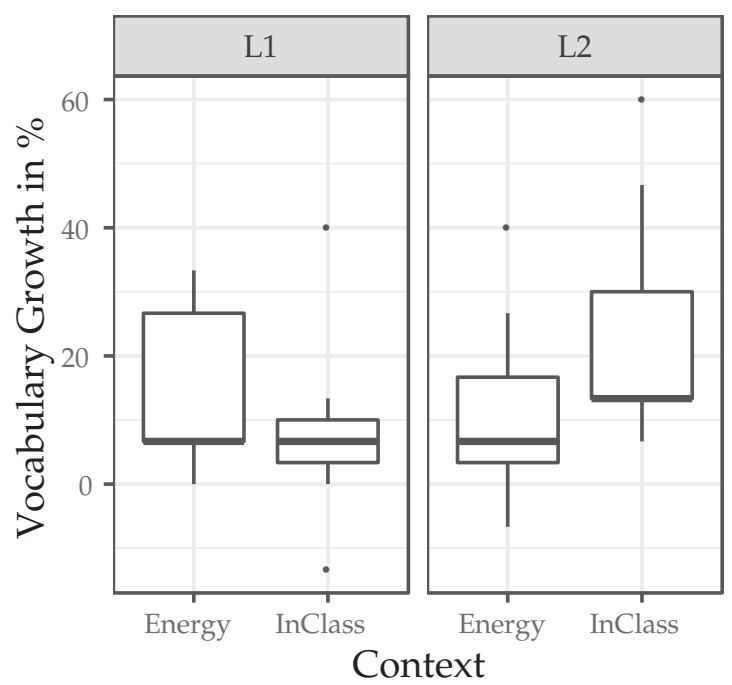

Figure 2: Boxplots of vocabulary growth (post-test percentage correct minus pre-test percentage correct) for the two language groups and learning contexts. Thick lines denote group medians; Boxes denote first and third quartiles; Whiskers denote 1.5 interquartile range; Single points denote outliers.

routines within the day care. The second limitation is the lack of a passive control group. Preferably, another group of children would have been tested that did not have access to the Energy Center at all. This would have allowed us to compare the baseline growth in vocabulary of the control group with the children who did play in the Energy Center.

\section{EXPERIMENT 2: LAB STUDY WITH DUTCH PRESCHOOLERS ACQUIRING ENGLISH VOCABULARY}

\section{Method}

Thirty-four Dutch monolingual preschoolers (seventeen females, mean age 3.79 years, range 2.4-3.8) were tested on their English vocabulary with a picture-word matching task after having played once in the Energy Center (English version). An additional fifteen children were tested but excluded from the analysis because they did not contribute at least half of the trials for each condition in the picture-word matching task. Parents gave informed written consent prior to data collection and were debriefed about the aim of the experiment after testing. Children did not know each other prior to their visit to the lab. Before playing in the Energy Center, children went through a picture-word matching phase (in English) on a tablet PC: eighteen pictures were shown consecutively on-screen. Each picture was either named ('Look! A bike! Touch it!', 'Look! A chair! Touch it!') or not named at all ('Look! How nice! Touch it!'). After this matching phase, children played in the Energy Center for as long as they wanted. The Energy Center featured two sets of three songs each (version A, twelve children tested, and version B, 22 children tested). The songs contained a subset of words from the matching phase (e.g. bike). During the test phase, children saw a set of three pictures on a tablet 


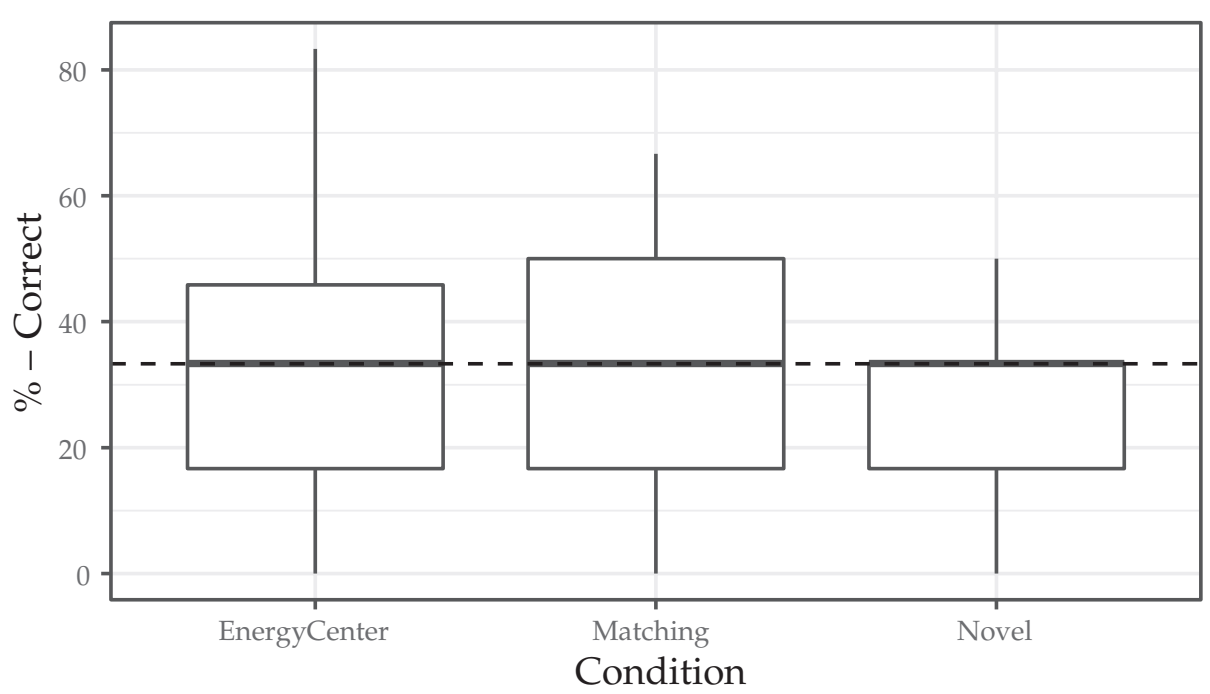

Figure 3: Percentage of correct responses in the three experimental conditions of experiment 2. Dashed line indicates chance level. Boxplots: thick lines denote group medians; Boxes denote first and third quartiles; Whiskers denote 1.5 interquartile range.

PC and were asked to touch the correct picture. The pictures were distributed across three conditions: novel $=$ not named during the matching phase (e.g. picture of a spoon); matching = named only during the matching phase of the experiment (e.g. chair); and Energy Center = named during the matching phase and in the songs of the Energy Center (e.g. bike).

\section{Results}

Children performed around chance level regardless of the experimental condition (see Figure 3).

A one-way repeated-measures ANOVA indicated no significant differences between the three experimental conditions (novel, matching, Energy Center) $(F<1)$.

\section{EXPERIMENT 3: FIELD STUDY IN INDIA WITH PRESCHOOLERS ACQUIRING ENGLISH VOCABULARY}

\section{Method}

Sixteen children (seven females, mean age 4.0 years) were recruited at the campus of Snehalaya Foundation in Ahmednagar, India. Children mainly had Hindi or Marathi as their first language and did not have English language lessons in the past. However, they regularly overhear volunteers visiting the campus speak English, and some children did know a couple of English words (e.g. tree, selfie). The age of the children was estimated after consulting their guardians due to a lack of official demographic information for this sample. Data collection was part of an official collaboration between the Snehalaya Foundation and Noplica, and the guardians of participating children gave oral consent prior to data collection. Children were tested on two consecutive days. On day one, children executed the Peabody Picture Vocabulary Test 
(Dunn and Dunn 1997) to assess individual differences in English vocabulary. On day two, children were tested in groups of three after they first listened to three songs from the Energy Center (English version). Each song was played three times. Children were sitting in a circle together with the researcher and a teaching assistant. They were instructed to move and clap along to the songs. After exposure to the songs, the matching phase began: the teaching assistant introduced the English vocabulary of the songs by showing the group of children pictures of the target words. Like in Experiment 2, the target words were distributed across three conditions: Energy Center songs (words being named in the songs from the Energy Center and during the matching phase), matching (words only being named during the matching phase but not in the songs) and novel (words not named at all). For the words in the song and matching condition, the teaching assistant would name the target word several times (e.g. 'Look! A bike! Bike! Bike!'). For the novel words, the teaching assistant held up the picture of the target word and only said 'Look!, How nice!'. During the test phase, children were tested individually. Like in Experiment 2, children now saw pictures of three target words at the same time and were asked to point at the right picture ('Show me the bike!').

\section{Results}

Children performed better in the matching and Energy Center condition than in the novel condition (Figure 4).

A non-parametric one-way repeated-measures ANOVA indicated a significant main effect of experimental condition $(F[1.92]=4.40, p=0.01)$. However, follow-up tests (using the'rmmcp' function) revealed no significant differences between conditions, probably due to the small sample size of the study.

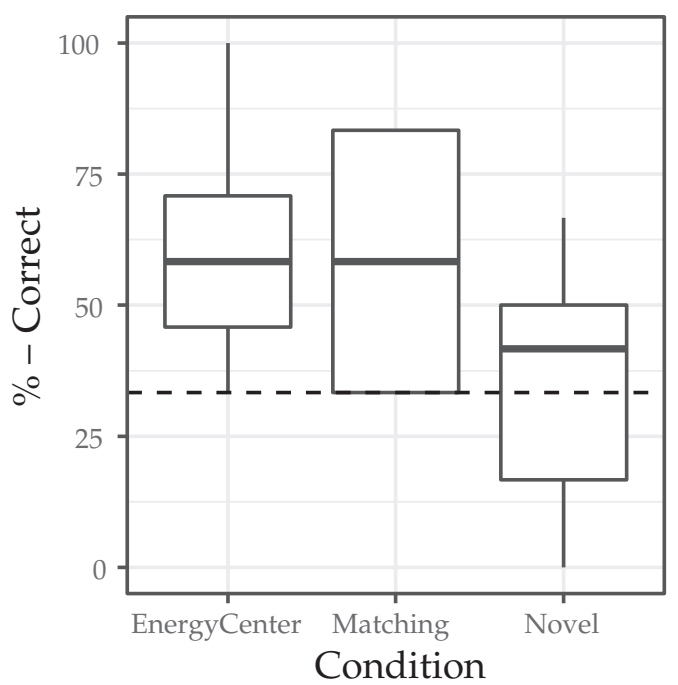

Figure 4: Percentage of correct responses in the three experimental conditions of experiment 3. Dashed line indicates chance level. Boxplots: thick lines denote group medians; Boxes denote first and third quartiles; Whiskers denote 1.5 interquartile range. 


\section{GENERAL DISCUSSION}

Taken together, the results of the three experiments are inconclusive, and we will provide a more in-depth interpretation in the following. Note that the small achievements observed (in Experiments 1 and 3) are comparable to those of previous studies (Mavilidi et al. 2015). In Experiment 1, a benefit of using the Energy Center was observed. Both L2 and L1-at risk children in a Dutch day care correctly identified more words after exposure to the songs of the Energy Center than before. It is unlikely that these words were acquired outside of the Energy Center - for example, in the day care - as we controlled the target words to be outside of the standard curriculum. While admittedly Experiment 1 missed a passive control group of children who did not have access to the Energy Center and featured only a small and heterogeneous group of children, the results indicate that the Energy Center could be a valuable tool for language learning. In Experiment 3, which was run in an Indian orphanage with L2 learners of English, performance was good on the words used in the songs of the Energy Center; however, the achievements were not better than for the words that only occurred in the matching phase. We were thus unable to prove an additional benefit of hearing the target words in the songs of the Energy Center. In Experiment 2, a well-controlled lab study with L2 learners of English, performance was around chance level in all three experimental conditions, rendering the results difficult to interpret.

There are important differences regarding the participants and the design of our experiments, which have likely influenced the results: higher learning outcomes were observed for healthy learners who already had some prior knowledge of the target language (L2 learners in Experiment 1). For participants who only knew very few words in the target language (Experiments 2 and 3) or were at risk for a language impairment (L1-at risk children in Experiment 1), learning from the Energy Center was more difficult. In terms of design, participants in Experiments 1 and 3 benefitted from the fact that they heard the songs of the Energy Center together with their peers in a familiar environment. In Experiment 2, children did not know each other and only met shortly before the test session started and were, therefore, less relaxed during the task. Due to the participants being rather shy, participants in Experiment 2 also had the shortest time of exposure to the songs of the Energy Center, as they preferred to stop cycling and proceed to the test phase. Finally, participants in Experiment 3 executed the matching phase right before the test phase, as opposed to Experiments 1 and 2, where participants cycled in the Energy Center between pre- and post-test (Experiment 1) or matching and test phase (Experiment 2). Therefore, in Experiment 3, it might have been easier to recall the items of the matching condition, due to the fact that these items were more recently heard.

Moreover, children in the current study were facing a rather difficult task: acquiring a set of novel words together with the words' meaning as depicted on an image. In addition to this challenging task, the functionality of the Energy Center and its songs were unfamiliar to the children. This combination of the experimental task and the novel game caused a high cognitive load under which the children had to process the content of the songs of the Energy Center. In future studies, an easier experimental task should be used to investigate the potential learning benefits of the Energy Center and its songs.

Songs are a natural context to teach novel vocabulary (Davis 2017; Engh 2013; Fonseca-Mora 2016), yet they are less ideal to acquire the meaning of a 
word (Schön et al. 2008). Instead, songs - just like poetry - allow for implicit acquisition and retention of the acoustic structure of a foreign language (Tillmann and Dowling 2007). Consequently, future studies should focus less on the acquisition of word meaning and more on learning phonological word forms in the Energy Center.

Another important future research topic pertains to the role of different learning environments and different types of movement in learning from the songs of the Energy Center. In the current study, participants in Experiments 1 and 2 were cycling independently in the Energy Center, while participants in Experiment 3 were sitting in a circle with two instructors and clapping along to the rhythm of the songs. The learning condition of Experiment 3 might be more ideal to pick up linguistic information from the songs, due to the clapping being entrained to the rhythm of the songs (Tierney and Kraus 2014) and the whole situation being more familiar and thus potentially less demanding for shy learners (Hilton and Westermann 2017). However, this in-class listening condition also requires an instructor/teacher to guide the learners through the songs and is rather static as children are sitting throughout the activity. The Energy Center, instead, has been developed as an unsupervised learning environment with free movement. Its stand-alone setup does not require a teacher or supervisor. While playing in the Energy Center, children also freely move around the hand-bikes and initiate and terminate movements upon their own will. The hand-bikes, in principle, also allow for rhythmic entrainment to the song rhythms just like clapping would (Tierney and Kraus 2014). However, for children to benefit from the Energy Center, they might need to cope with more noise in the environment (both auditory and visual). This could be achieved by familiarizing the children to the learning environment through regular access to the Energy Center. During these visits, they could get used to the movements, the songs and their lyrics. Once children are provided enough repetition of the learning material and enough time to play the game, successful learning is possible (van Zeeland and Schmitt 2013).

\section{CONCLUSION}

The Noplica Energy Center provides an enthralling combination of music and movement and makes for a promising means for language learning in preschool children. For the Energy Center to work best, it seems crucial for it to be integrated within the daily activities of children - for example, within a day care - so that children can access the Energy Center over the course of several weeks. Moreover, children should have some prior experience with the language that is featured in the Energy Center. Once children can play the game regularly and together with their peers, successful learning is possible. However, more wellpowered studies are necessary before firm conclusions can be drawn.

\section{ACKNOWLEDGEMENTS}

This work was supported by a grant from the Centre for Language Studies, Radboud University, Nijmegen, the Netherlands. We thank our assistants at Snehalaya Campus (Maharashtra, India) and Pino, a KION day care centre in Nijmegen, for their enthusiastic support. We also thank Julia Merkus, Demi Lamers, Anna Bolhuis and Katharina Menn who supported us during preparation and testing of the study, and Peter Withers who programmed the picture-word matching task for a tablet PC. 


\section{REFERENCES}

Barenberg, J., Berse, T. and Dutke, S. (2011), 'Executive functions in learning processes: Do they benefit from physical activity?', Educational Research Review, 6:3, pp. 208-22.

Barsalou, L. W. (2008), 'Grounded cognition', Annual Review of Psychology, 59:1, pp. 617-45.

Benz, S., Sellaro, R., Hommel, B. and Colzato, L. S. (2016), 'Music makes the world go round: The impact of musical training on non-musical cognitive functions - A review', Frontiers in Psychology, 6:2023 (January), pp. 1-5.

Calvert, S. L. and Billingsley, R. L. (1998), 'Young children's recitation and comprehension of information presented by songs', Journal of Applied Developmental Psychology, 19:1, pp. 97-108.

Cirelli, L. K., Jurewicz, Z. B. and Trehub, S. E. (2019), 'Effects of maternal singing style on mother-infant arousal and behavior', Journal of Cognitive Neuroscience, 24:6, pp. 1275-85.

Cohrdes, C., Grolig, L. and Schroeder, S. (2016), 'Relating language and music skills in young children: A first approach to systemize and compare distinct competencies on different levels', Frontiers in Psychology, 7:1616 (October), pp. 1-11.

Coyle, Y. and Gomez Gracia, R. (2014), 'Using songs to enhance L2 vocabulary acquisition in preschool children', ELT Journal, 68:3, pp. 276-85.

Davis, G. M. (2017), 'Songs in the young learner classroom: A critical review of evidence', ELT Journal, 71:4, pp. 445-55.

Donnelly, J. E., Hillman, C. H., Castelli, D., Etnier, J. L., Lee, S., Tomporowski, P., Lambourne, K. and Szabo-Reed, A. N. (2017), 'Physical activity, fitness, cognitive function, and academic achievement in children: A systematic review', Medicine and Science in Sports and Exercise, 48:6, pp. 1197-222.

Dunn, L. M. and Dunn, L. M. (1997), PPVT-III: Peabody Picture Vocabulary Test, Circle Pines, MN: American Guidance Service.

Elmer, S. and Jäncke, L. (2018), 'Relationships between music training, speech processing, and word learning: A network perspective', Annals of the New York Academy of Sciences, 1423:1, pp. 10-18.

Engh, D. (2013), 'Why use music in English language learning? A survey of the literature', English Language Teaching, 6:2, pp. 113-27.

Finger, J. D., Varnaccia, G., Borrmann, A., Lange, C. and Mensink, G. B. M. (2018), 'Körperliche Aktivität von Kindern und Jugendlichen in Deutschland -Querschnittergebnisse aus KiGGS Welle 2 und Trends', Journal of Health Monitoring, 3:1, pp. 24-31.

Fisher, K. R., Hirsh-Pasek, K., Golinkoff, R. M. and Gryfe, S. G. (2008), 'Conceptual split? Parents' and experts' perceptions of play in the 21st century', Journal of Applied Developmental Psychology, 29:4, pp. 305-16.

Fisher, K. R., Hirsh-Pasek, K., Golinkoff, R. M., Singer, D. G. and Berk, L. (2012), 'Playing around in school: Implications for learning and educational policy', in P. Nathan and A. D. Pelligrini (eds), The Oxford Handbook of the Development of Play, Oxford: Oxford University Press, pp. 1-37.

Fonseca-Mora, C. (2016), Melodies, Rhythm and Cognition in Foreign Language Learning (eds C. Fonseca-Mora and M. Gant), Newcastle upon Tyne: Cambridge Scholars Publishing.

Gezondheidsraad (2017), Beweegrichtlijnen 2017, Den Haag: Gezondheidsraad.

Golinkoff, R. M., Hirsh-Pasek, K. A. and Singer, D. G. (2006), 'Play = learning: A challenge for parents and educators', in R. M. Golinkoff, K. A. 
Hirsh-Pasek and D. G. Singer (eds), Play = Learning: How Play Motivates and Enhances Children's Cognitive and Social-Emotional Growth, Oxford: Oxford University Press, pp. 1-21.

Griffiths, L. J., Cortina-Borja, M., Sera, F., Pouliou, T., Geraci, M., Rich, C., Cole, T. J., Law, C., Joshi, H., Ness, A. R., Jebb, S. A. and Dezateux, C. (2013), 'How active are our children? Findings from the millennium cohort study', BMJ Open, 3:8, pp. 1-10.

Herting, M. (2018), 'Exercise effects in cognition and motor learning', in H. Budde and M. Wegner (eds), The Exercise Effect on Mental Health, Neurobiological Mechanisms, New York and London: Routledge and Taylor \& Francis Group, pp. 225-46.

Hilton, M. and Westermann, G. (2017), 'The effect of shyness on children's formation and retention of novel word - Object mappings', Journal of Child Language, 44, pp. 1394-1412.

Ilari, B. (2015), 'Music in the early years: Pathways into the social world', Research Studies in Music Education, 38:1, pp. 23-39.

- (2018), 'Scaramouche goes to preschool: The complex matrix of young children's everyday music', Early Childhood Education Journal, 46:1, pp. 1-9.

Leśniewska, J. and Pichette, F. (2014), 'Songs vs. stories: Impact of input sources on ESL vocabulary acquisition by preliterate children', International Journal of Bilingual Education and Bilingualism, 19:1, pp. 1-17.

Linnavalli, T., Putkinen, V., Lipsanen, J., Huotilainen, M. and Tervaniemi, M. (2018), 'Music playschool enhances children's linguistic skills', Scientific Reports, 8:1, pp. 1-10.

Liu, F., Sulpizio, S., Kornpetpanee, S. and Job, R. (2017), 'It takes biking to learn: Physical activity improves learning a second language', PLoS One, 12:5, pp. 1-15.

Marsh, K. and Young, S. (2016), 'Musical play', in G. McPherson (ed.), The Child as a Musician, New York: Oxford University Press, pp. 462-84.

Mavilidi, M. F., Okely, A. D., Chandler, P., Cliff, D. P. and Paas, F. (2015), ‘Effects of integrated physical exercises and gestures on preschool children's foreign language vocabulary learning', Educational Psychology Review, 27:3, pp. 413-26.

Mavilidi, M. F., Okely, A., Chandler, P., Louise Domazet, S. and Paas, F. (2018), 'Immediate and delayed effects of integrating physical activity into preschool children's learning of numeracy skills', Journal of Experimental Child Psychology, 166, pp. 502-19.

Patel, A. D. (2011), 'Why would musical training benefit the neural encoding of speech? The OPERA hypothesis', Frontiers in Psychology, 2, June, p. 142.

- (2012), 'The OPERA hypothesis: Assumptions and clarifications', Annals of the New York Academy of Sciences, 1252:1, pp. 124-28.

- (2014), 'Can nonlinguistic musical training change the way the brain processes speech? The expanded OPERA hypothesis', Hearing Research, 308, pp. 98-108.

Pellegrini, A. D. (2012), 'The development and function of locomotor play', in P. Nathan and A. D. Pellegrini (eds), The Oxford Handbook of the Development of Play, Oxford: Oxford University Press, n.pag.

Reilly, E., Buskist, C. and Gross, M. K. (2012), 'Movement in the classroom: Boosting brain power, fighting obesity', Kappa Delta Pi Record, 48:2, pp. 62-66.

Schmidt, M., Benzing, V., Wallman-Jones, A., Mavilidi, M. F., Lubans, D. R. and Paas, F. (2019), 'Embodied learning in the classroom: Effects on primary 
school children's attention and foreign language vocabulary learning', Psychology of Sport and Exercise, 43, pp. 45-54.

Schön, D., Boyer, M., Moreno, S., Besson, M., Peretz, I. and Kolinsky, R. (2008), 'Songs as an aid for language acquisition', Cognition, 106:2, pp. 975-83.

Smith, P. K. (2010), Children and Play, Chichester: Wiley-Blackwell.

Strait, D. L. and Kraus, N. (2011), 'Playing music for a smarter ear: Cognitive, perceptual and neurobiological evidence', Music Perception, 29:2, pp. 133-46.

Tierney, A. and Kraus, N. (2014), 'Auditory-motor entrainment and phonological skills: Precise auditory timing hypothesis (PATH)', Frontiers in Human Neuroscience, 8, p. 949.

Tillmann, B. and Dowling, W. J. (2007), 'Memory decreases for prose, but not for poetry', Memory \& Cognition, 35:4, pp. 628-39.

Trehub, S. E. and Cirelli, L. K. (2018), 'Precursors to the performing arts in infancy and early childhood', in J. F. Christensen and G. Antoni (eds), Progress in Brain Research, vol. 237, Cambridge, MA: Elsevier B.V., pp. 225-42.

Wilcox, R. R. (2012), Modern Statistics for the Social and Behavioral Sciences, Boca Raton, FL: CRC Press.

Wilcox, R. R. and Schönbrodt, F. D. (2014), 'The WRS package for robust statistics in $\mathrm{R}$ (version 0.24$)^{\prime}$.

Wilson, M. (2002), 'Six views of embodied cognition', Psychonomic Bulletin and Review, 9:4, pp. 625-36.

van Zeeland, H. and Schmitt, N. (2013), 'Incidental vocabulary acquisition through L2 listening: A dimensions approach', System, 41:3, pp. 609-24.

\section{SUGGESTED CITATION}

Hahn, Laura E., ten Buuren, Maaike, Snijders, Tineke M. and Fikkert, Paula (2020), 'Learning words in a second language while cycling and listening to children's songs: The Noplica Energy Center', International Journal of Music in Early Childhood, 15:1, pp. 95-108, doi: https://doi.org/10.1386/ ijmec_00014_1

\section{CONTRIBUTOR DETAILS}

Laura E. Hahn is a Ph.D. student at the Centre for Language Studies at Radboud University Nijmegen, the Netherlands. She is interested in early language play, like songs and nursery rhymes, and their potential contribution to language acquisition. In her behavioural and EEG studies, she investigates infants' ability to pick up rhymes, rhythm and phrase boundaries from language play and the relationship of these abilities with infants' vocabulary development.

Contact: Centre for Language Studies, Radboud University, PO Box 9103, 6500 HD Nijmegen, The Netherlands.

E-mail: 1.hahn@let.ru.nl

D https://orcid.org/0000-0002-3559-5687 
Maaike ten Buuren contributed the data from the Indian field site as part of her Master's thesis for the study program Linguistics at Radboud University Nijmegen. She also holds a degree in Orthopedagogy, and currently, works as a practitioner for children with learning problems.

Tineke M. Snijders is a senior researcher at the Max Planck Institute for Psycholinguistics and investigates the role of neuronal rhythms in early language acquisition. She has published on the neurocognition of language of adults and on infants' word learning from songs using behavioural and neuroimaging methods.

Contact: Max Planck Institute for Psycholinguistics, P.O. Box 310, 6500 AH Nijmegen, The Netherlands.

E-mail: tineke.snijders@mpi.nl

(1) https://orcid.org/0000-0002-2442-0451

Paula Fikkert is a professor for First Language Acquisition and Phonology at Radboud University Nijmegen, the Netherlands, www.fikkert.com. Her research interests encompass perceptual asymmetries of phonological contrasts and the underlying mental representations in children's language perception and production. As a scientific advisor to the ChildTuition foundation, she designed the linguistic content of the Noplica Playhouse described in the current study.

Contact: Centre for Language Studies, Radboud University, PO Box 9103, 6500 HD Nijmegen, The Netherlands.

E-mail: p.fikkert@let.ru.nl

(D) https://orcid.org/0000-0001-7317-2100

Laura E. Hahn, Maaike ten Buuren, Tineke M. Snijders and Paula Fikkert have asserted their right under the Copyright, Designs and Patents Act, 1988, to be identified as the authors of this work in the format that was submitted to Intellect Ltd. 